\section{Shoulder-hand syndrome in patients with ovarian carcinoma}

SIR. Following the recent report by Taggart et al. ' we wish to report a further case of severe shoulder-hand syndrome in a patient with ovarian carcinoma. This 43 -year-old patient presented in November 1983 with ascites. At laparotomy she was found to have peritoneal spread of an undifferentiated ovarian adenocarcinoma. She was treated with treosulfan in a dose of $250 \mathrm{mg}$ twice daily for one week. followed by two weeks off, for a period of several months. The treatment was followed by shrinkage of peritoneal fluid and improvement in general well-being. In April 1984 she began to complain of pain and swelling in her hands and shoulders and discomfort in her knees and ankles. Both hands were oedematous and the skin eventually became fixed to the underlying tissues, especially in her fingers. where she developed severe fixed flexion deformities. Similar changes were observed in here feet. Her shoulders were stiff and painful. Treosulfan was stopped and prednisolone was given in a dose of $30 \mathrm{mg}$ daily This reduced the discomfort in her shoulders, but had littleo effect on the oedema and eventual fibrotic sclerodermatou듀 appearance of her hands, which remained unchanged untiE her death in June 1984.

Dept of Rheumatology

Stobhill General Hospital

Glasgow G21 3UW

University of Glasgow

P E MCGILI)

\section{References}

1 Taggart A J. Iveson J M I. Wright V. Shoulder-hand syndrom and symmetrical arthralgia in patients with tubo-ovarian carcinoma. Ann Rheum Dis 1984: 43: 391-3.

\title{
Notes
}

\section{'Viewpoint' articles}

Under this general heading articles will appear which are intended to present a personal view of themes currently interesting to rheumatologists. Contributions in not more than 1500 words are welcome, but it is suggested that readers wishing to submit such articles should first discuss their subject and scope with the Editor.

\section{The Third Carl M Pearson Memorial Symposium}

This symposium on the 'Frontiers of Rheumatology' wi $\mathbb{B}$ be held on 8-10 March 1985 at the Annenberg Center fo? Health Sciences, California. Details from the Annenberg. Center for Health Sciences, Eisenhower Medical Center 39000 Bob Hope Drive, Rancho Mirage, CA 92270, USA 